\title{
Correction \\ Correction: Rubiola et al. Risk Factors for Bovine Cysticercosis in North-West Italy: A Multi-Year Case-Control Study. Animals 2021, 11, 3049
}

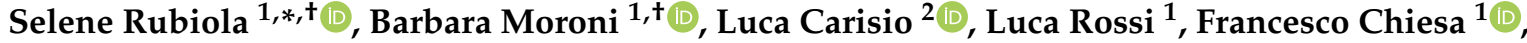 \\ Giuseppe Martano ${ }^{3}$, Elisa Cavallo ${ }^{3}$ and Luisa Rambozzi ${ }^{1}(\mathbb{D}$
}

check for

updates

Citation: Rubiola, S.; Moroni, B.;

Carisio, L.; Rossi, L.; Chiesa, F.;

Martano, G.; Cavallo, E.; Rambozzi, L.

Correction: Rubiola et al. Risk

Factors for Bovine Cysticercosis in

North-West Italy: A Multi-Year

Case-Control Study. Animals 2021, 11, 3049. Animals 2022, 12, 636. https://

doi.org/10.3390/ani12050636

Received: 10 February 2022

Accepted: 15 February 2022

Published: 3 March 2022

Publisher's Note: MDPI stays neutral with regard to jurisdictional claims in published maps and institutional affiliations.

Copyright: (c) 2022 by the authors. Licensee MDPI, Basel, Switzerland. This article is an open access article distributed under the terms and conditions of the Creative Commons Attribution (CC BY) license (https:// creativecommons.org/licenses/by/ $4.0 /)$.
1 Department of Veterinary Sciences, University of Turin, Largo Paolo Braccini 2, 10095 Grugliasco, Italy; barbara.moroni@unito.it (B.M.); luca.rossi@unito.it (L.R.); francesco.chiesa@unito.it (F.C.); luisa.rambozzi@unito.it (L.R.)

2 Department of Agricultural, Forest and Food Sciences, University of Turin, Largo Paolo Braccini 2, 10095 Grugliasco, Italy; luca.carisio@unito.it

3 ASL TO3, Animal Health, Via Martiri XXX Aprile 30, 10093 Collegno, Italy; gmartano@aslto3.piemonte.it (G.M.); ecavallo@aslto3.piemonte.it (E.C.)

* Correspondence: selene.rubiola@unito.it

+ These authors contributed equally to this work.

Error in Institutional Review Board Statement [1]:

In the original publication, the Institutional Review Board Statement was incorrect. The authors apologize for the omission and for any inconvenience caused, and state that the scientific conclusions are unaffected. The original publication has also been updated.

Corrected Institutional Review Board Statement:

"The authors confirm that this study has been ethically reviewed by the Bio-Ethics Committee of the University of Turin [UOR: SI000045-Classif. III/11] under protocol number 0011298 and that ethical approval was granted in January 2012."

\section{Reference}

1. Rubiola, S.; Moroni, B.; Carisio, L.; Rossi, L.; Chiesa, F.; Martano, G.; Cavallo, E.; Rambozzi, L. Risk Factors for Bovine Cysticercosis in North-West Italy: A Multi-Year Case-Control Study. Animals 2021, 11, 3049. [CrossRef] [PubMed] 